Vol. 1, No. 1

Vitoria - ES, Jan - Jun. 2004

DOI : http://dx.doi.org/10.15728/bbr.2004.1.1.5

pp. $63-73$

\title{
Measuring Cost Efficiency in the Brazilian Electricity Distribution Sector
}

\author{
Wagner Montoro Júnior \\ IBMEC Rio de Janeiro \\ Arilton Teixeira \\ FUCAPE - Capixaba Foundation for Research in Accounting, \\ Economy and Finance
}

\begin{abstract}
The objective of the this work is to verify the applicability of parametric methods that measure the cost efficiency of Brazilian electricity distributors. We estimate total cost functions, derived from a Cobb-Douglas production function. The frontier cost model is estimated using GLS (Variance Components - Random Effects) and pooled least square (Fixed Effects) methods. We apply these methods to a sample of 25 Brazilian power distribution companies over a period of 12 years, from 1990 through 2001. The results indicate that in the period studied all the companies were equally efficient in controlling their costs.
\end{abstract}

Key words: cost efficiency, distribution, electricity sector.

\section{Arilton Teixeira}

Doutor em Economia

Fucape Business School

Adress: Av. Fernando Ferrari, Boa Vista, Vitória - ES

- Brasil, CEP: 29075-505

Email: arilton@fucape.br

Telephone: 2740094402
Wagner Montoro Júnior

Adress: Av. Fernando Ferrari, Boa Vista, Vitória - ES - Brasil, CEP: 29075-505

Telephone: 274009440 


\section{INTRODUCTION}

ransmissioin and distribution of electric power were considered natural monopolies and thus have been less affected by the recent wave of deregulation in the Brazilian energy sector. However, with the introduction of competition in the generation segment in the 1980s, regulatory reform and efficiency incentives have become more common. In the traditional Brazilian system of regulated prices to consumers, companies recouped their costs with a guaranteed risk-free rate of return, so they had little impetus to minimize costs.

On the other hand, regulatory schemes based on incentives are structured to provide a stimulus for efficiency, positively compensating companies for cutting costs. A variety of methods are proposed in the literature. Moving rates of return, regulatory schemes with price or revenue caps, yardstick regulation and contract menus are the main schemes applied to the sector $^{1}$. Jamasb and Pollitt conducted an extensive survey of the different regulatory practices in diverse countries. Virtually all of the regulatory models seeking cost efficiency using incentives are based on benchmarking, measuring a firm's efficiency against a performance reference.

We should consider that cost inefficiency is a deviation from the optimum point of production or the cost frontier. This deviation can result from two sources: technical deficiencies and problems of poor allocation of productive resources. Both these cases technical and allocative - are included in cost inefficiency, which by definition is the divergence from the minimum production cost, given a certain level of production and of input costs.

There is a large variety of methods to measure cost efficiency. These range from basic indicators to more complex measures obtained from multivariate analyses. The basic indicators are simple measures, such as average unit cost or average work productivity, and are commonly used in practice. However, they fail by to consider the differences between the conditions and opportunities of various company profiles. Rossi and Ruzzier (2000) supply a comparative discussion of the different approaches used in a cross sectional study using panel data. One of the main advantages of parametric models is their ability to control for the unobserved heterogeneity among companies. In particular, panel data models are better able to control for the possibility that such dissimilarities exist. Hence, this model has become an important subject for the electricity distribution sector, where different firms deal with various consumer types and densities and different geographic conditions. These factors, as well as other unobserved characteristics, potentially affect costs but do not necessarily indicate different efficiency levels. The inefficiency measured can be affected by these factors, confounding the evaluations. Hence, companies that face unobserved unfavorable conditions can be classified mistakenly as inefficient producers.

The theoretical development of stochastic frontier models using panel data has been the subject of many studies in the specialized literature ${ }^{2}$. The results suggest that the reliability of different models depends on the nature of the production. In sectors like electricity distribution, production technology is a very complex function that depends on a range of external parameters associated with the production environment and demand characteristics. Production methods improve over time and it is important to capture these advances in the production functions. Initially a certain combination of capital and labor can be used to

\footnotetext{
${ }^{1}$ See Jamasb and Pollitt (2000) and Joskow and Schmalensee (1986) on regulatory models.

${ }^{2}$ See Greene (2001).
}

BBR, Braz. Bus. Rev. (Eng. ed., Online), 
achieve a given level of output, but with the development of superior technologies it becomes possible to attain the same level of production with fewer inputs. A way to measure technical progress is to verify whether the output level initially obtained with a given volume of capital and labor is also obtained with a lower volume of labor. Output per worker grows. However, caution in this assessment is in order because an increase in the amount of capital can also lead to greater worker productivity. The use of an adequate production function can help to differentiate the two phenomena and permit obtaining an accurate estimate of the rate of technological progress. The first observation to be made about technological progress is that historically the rate of output growth over time exceeds the growth of production itself, from the conventional point of view.

Studies by Prescott (1997) indicate that technical progress, measured by the variations in total factor productivity, can be used to evaluate the economic growth of countries, by means of direct correlation with the change in per capita income, which is an indication of labor productivity.

Focusing on parametric methods, using different panel data models, and inspired by the use of the denotative potential of total factor productivity, this work aims to study to what point we can apply the technological progress factor, expressed in a Cobb-Douglas function adopted as an efficiency indicator. We try to show that the levels of inefficiency can be measured by presuming that the greater the technological progress factor is, the less will be cost function, and consequently, the more efficient the company will be. Section 2 describes the microeconomic theory applied in defining the cost and production functions adopted and the concept of efficient frontier costs. Section 3 describes the data used in this study and the way they were gathered. Section 4 demonstrates the results obtained in the estimation, and Section 5 presents the conclusions.

\section{METHODOLOGY}

According to the microeconomic theory of cost minimization, we must assume that companies, starting from their production factors, want to achieve the cheapest way to reach a given level of output. The solution to this problem will depend on the prices of the production factors and the level of output desired. In this form, the solution will be a cost function, which will define minimum costs for a given level or output, factor prices and technical constraints on output. When we represent this problem of costs and restrictions graphically through isoquants, we find that the optimal choice, which minimizes costs, is determined by finding the point in the isoquant that is associated with lowest isocost. In the electric power sector, it is unlikely that all companies will operate at this frontier. A weakness in attaining the frontier cost implies the existence of technical and allocative inefficiencies. From a theoretical standpoint we can assume that the activity of electricity distribution can be represented according to a Cobb-Douglas production function

$$
q=A K^{\alpha} L^{\beta}
$$

where output $(q)$ depends on the amount of capital $(K)$ and the amount of labor $(L)$, both being subject to a technological progress factor.

With the unit cost of capital represented by $v$ and the unit cost of labor by $w$, we have that the total production will be given by 


$$
C T=v K+w L
$$

We now consider a cost minimization problem such that

$$
C(w, r, q)=\min _{K, L} \quad\{r K+w L\}
$$

Subject to $q=A K^{\alpha} L^{\beta}$

Resolving this problem, we find that the cost function is equivalent to:

$$
\begin{aligned}
& C(w, v, q)=v K(w, r, q)+w L(w, r, q) \\
& =A^{\overline{\alpha+\beta}}\left[\left(\frac{\alpha}{\beta}\right)^{\overline{\alpha+\beta}}+\left(\frac{\alpha}{\beta}\right)^{\frac{-\alpha}{\alpha+\beta}}\right] r^{\bar{\alpha}} w^{\overline{\alpha+\beta}} q^{\overline{\alpha+\beta}}
\end{aligned}
$$

where $K(w, r, q)$ and $L(w, r, q)$ are conditional demand factor functions, i.e., how much of each factor the company uses to reach a determined level of output in the most efficient form from a cost standpoint.

Equation (1) identifies the influence of technological progress on the cost function, through the factor $\boldsymbol{A}$, which is the key piece in this study. We try to measure the cost factor of electricity concessionaires by means of the total factor productivity, bearing in mind that this factor $\boldsymbol{A}$ will inversely indicate the firm's capacity to make its production costs more efficient. In other words, the greater this factor is, the smaller will be the result of the cost function and consequently the more efficient the company will be. It should be stressed that all the utilities considered in this work operate in the Brazilian power distribution market, and are thus subject to the same macroeconomic conditions. Through the total factor productivity, estimated over the study horizon, we seek to evaluate productive efficiency, more specifically regarding control of operating costs. The estimation of such factors will indicate which companies achieve greater technological progress, a lower output cost function and therefore greater cost efficiency.

Technological advance is fundamental in the entire production process. From the point of view of output, a production plan is said to be efficient if there is no way to produce more with the same inputs or to produce the same quantity with fewer inputs. In the electricity distribution sector, technological progress helps to cut losses, both technical and commercial, and to modernize the materials and equipment employed in building distribution networks than it does to boost energy output or expand the market. Technologically advanced distribution companies invest intensely in technologies for measurement of consumption, remote controls and detection of losses..

\subsection{Specification of the Frontier Cost Function}

Electricity distribution companies operate networks with different profiles, which directly affect their costs. As discussed by Robert (1986), Salvanes and Tjota (1994) and Thompson (1997), the cost function should account for the differences among a network's characteristics and other factors that are not directly correlated with efficiency but do affect costs.. Here we basically use the specification of the model utilized by Filippini (1998). Production is measured by the total number of $\mathrm{kWh}$ delivered to consumers. The inputs for 
the power distribution process consist mainly of labor, capital and the electricity itself. The total cost of a distributor can be represented by:

$C=C(E N E R, D F I N, P E S, C O M B, D E C, T, D U M)(2)$

where $\mathrm{C}$ represents the total cost, ENER is the quantity of energy supplied in $\mathrm{kWh}, D F I N$ is the company's cost of own capital, estimated as proposed by Sanvicente and Minardi (2002), $P E S$ is the average expense per employee, $C O M B$ is the tariff paid for power for resale (supply), $D E C$ is a service quality measure, $D U M$ is a dummy variable to distinguish the existence of two periods, one before and the other after Brazil floated (devalued) its currency in early 1999, and $T$ is a time variable representing the linear trend of technological advance.

The regularity conditions require that the cost function of equation (1) be linearly homogenous as to price inputs, non-decreasing and concave. The Cobb-Douglas model is one of the main functions commonly used in the literature. The Cobb-Douglas specification of the cost function in (1) can be written as:

$$
\ln \left(\frac{C}{C O M B}\right)=\beta_{0}+\beta_{Y} \ln E N E R+\beta_{K} \ln D F I N+\beta_{L} \ln \mid\left(\frac{P E S}{C O M B}\right)+\gamma_{1} \ln D E C+\delta_{1} D U M+\tau_{T} T
$$

Because of the homogeneity of the prices of inputs, the money values are divided by the price of power purchased for resale.

\section{THE DATA}

The data employed in this work consist of an unbalanced panel of 25 Brazilian electricity distributors over a period of 12 years, from 1990 to 2001. The sample includes 281 observations. These data were mainly gathered from the information contained in the annual reports and financial statements, obtained from the companies themselves or the files of Centrais Elétricas Brasileiras - Eletrobrás. The study horizon was not extended to more recent years because of the difficulty of getting data from some companies, in turn due to the change of some controlling shareholders, which have hindered access to information. This type of problem is inherent in studies relying on panel data ${ }^{3}$.

There are approximately 60 power distribution companies in Brazil. This sector is characterized by firms of varied sizes, but when compared with their counterparts in other countries they can be considered as medium to large firms. The sample used in this study, then, can be considered as representative of relatively large distributors in the Brazilian context. Despite a considerable degree of variation in costs and other characteristics, the sample represents similar companies when compared to the sector as a whole.

Table 1 summarizes the statistics summarized by the variables used in this analysis. We converted all amounts in Brazilian currency to U.S. dollars at the average annual exchange rate obtained from the IPEA DATA database. We considered the companies' annual cost $(\mathrm{C})$ as being the operating cost booked annually in the statement of income of the

\footnotetext{
${ }^{3}$ According to L. D. Marques (2000), econometric analyses with panel data are not immune from data collection problems.
} 
financial statements. The variable $C O M B$ corresponds to the average tariff paid for supply, since the distributors buy power from more than one generator. For distributors that generate part of their own energy, we considered its cost as equal to the lowest supply tariff effectively paid by that company to generators. The values for labor (PES) were defined as the average annual expense for wages and other payroll costs divided by the number of employees. The variable DFIN is the cost of own capital, estimated as proposed by Sanvicente and Minardi (2002). This variable is measured as a percentage - the lower the percentage, the lower the company's cost of capital. The variable $D E C$ measures the average time in minutes of power interruption, characterizing a failure in the distribution system.

\section{TABLE 1}

Descriptive Statistics

\begin{tabular}{|l|c|c|c|c|}
\hline & Mean & $\begin{array}{l}\text { Standard } \\
\text { Deviation }\end{array}$ & Minimum & Maximum \\
\hline $\begin{array}{l}\text { Total energy consumption } \\
\text { (Gigawh) - ENER }\end{array}$ & $4,652.60$ & $6,518.22$ & 165.56 & $38,618.16$ \\
\hline Cost of own capital (\%) DFIN & 43.84 & 13.00 & 34.53 & 139.42 \\
\hline $\begin{array}{l}\text { Average supply tariff COMB (in } \\
\text { US\$/Mwh) }\end{array}$ & 51.17 & 12.97 & 14.84 & 93.72 \\
\hline $\begin{array}{l}\text { Average annual wages per } \\
\text { employee (1000 US\$) PES }\end{array}$ & 23.63 & 10.55 & 6.12 & 68.18 \\
\hline $\begin{array}{l}\text { Power outage time DEC } \\
\text { (minutes) }\end{array}$ & 49.8 & 71.8 & 5.9 & 575.0 \\
\hline
\end{tabular}

\section{RESULTS OF THE ESTIMATION}

According to the results shown in Table 2, it can be stated that the estimators of energy sold (ENER) and interruption in supply (DEC) are different between the models presented. These differences suggest that the estimation may be sensitive to the specific characteristics of each company, which comes as no surprise in the power distribution sector. In the Fixed Effects model (pooled least square), the estimators are based on the assumption that the unobserved random variations are not specified. In contrast, in the Random Effects model (variance components), it is assumed that there are hidden specificities among the firms, but that the heterogeneities among them are not correlated with the observed characteristics. In the absence of more precise information on the unobserved heterogeneity among the firms, the Fixed Effects model could supply more realistic estimations about thefactors.

A special word is in order for the estimator that represents the linear trend to technological progress $(\mathrm{T})$. It was not statistically significant, indicating that no effect was identified due to technological advance in any of the companies studied over the period.

Although the results indicate that the estimates, both for Random Effects and Fixed Effects, are statistically significant, at the 5\% level (p-value of 0.055), the estimators of the Fixed Effects model turned out inconsistent, since there was a negative coefficient for the ENER factor, corresponding to the cost of power purchased, in reality an obviously positive factor. 


\begin{tabular}{|c|c|c|c|c|}
\hline \multicolumn{5}{|c|}{$\begin{array}{c}\text { TABLE } 2 \\
\text { Frontier Cost Factors }\end{array}$} \\
\hline & \multicolumn{2}{|c|}{ Fixed Effects } & \multicolumn{2}{|c|}{ RandomEffects (GLS) } \\
\hline & Coefficient & Std. Error & Coefficient & Std. Error \\
\hline LOG(PES/COMB) & 0.360978 & 0.079985 & 0.350610 & 0.080220 \\
\hline LOG(ENER) & -0.797723 & 0.384687 & 0.868791 & 0.053142 \\
\hline LOG(DFIN/COMB) & 0.138131 & 0.070024 & 0.146165 & 0.069392 \\
\hline LOG(DEC) & -0.023792 & 0.067693 & 0.054313 & 0.056895 \\
\hline$(\mathrm{T})$ & -0.038026 & 0.025672 & -0.138752 & 0.010861 \\
\hline (DUM) & 0.187289 & 0.085112 & 0.181829 & 0.087689 \\
\hline R-squared & 0.924420 & & 0.910431 & \\
\hline
\end{tabular}

Table 3 shows the estimators according to the two models for the technological progress factor considered in the cost function. The estimators are positioned to indicate both results, for the companies that presented cost efficiency based on the weight of the technological progress factor.

When observing the ten companies with the lowest factors, five of them appear in both models. From the standpoint of financial performance, of the five firms that are indicated as least efficient in the two models, three have historically shown significant indices of technical and commercial losses. They have frequent operational reference difficulties, recording lower revenues than expenses. In this group we can cite CEAM, responsible for supplying electricity to the state of Amazonas, CEAL, which operates in the state of Alagoas, and CEMAR, which recently was under intervention from the National Electric Energy Agency (ANEEL), since after repeated losses it was declared insolvent and returned to the government by the controlling private shareholder. Two of these companies (CEAM and CEAL) were originally transferred by their state owners to the federal government for the purpose of being put into shape for privatization. Nevertheless, they never were sold off and have remained in federal hands, since they do not have the minimum conditions to stand on their own as private companies. On the other hand, of the ten companies classified as most efficient, five are indicated in the two models, and of these three have low indices of losses and operate in the interconnected systems, supplied by hydro-power, where the costs of energy for resale are lower. We can mention CERJ and COELBA, which have strong cash flows and important consumer markets.

Strictly from the standpoint of the results obtained from the models, we find that the estimators of the Random Effects model are "better behaved" when compared with those of the Fixed Effects model, despite the correlation described above. However, the fact that we find estimators with negative sign for the ENER variable in the Fixed Effects model indicates that these results must be treated as unacceptable, since this variable has to have a positive sign in the proposed cost function. 
It thus remains to verify the results generated by the Random Effects model. This requires applying a test for the regressors obtained in that model, in order to determine to what point the components of the errors are present in the results.

TABLE 3

Estimators of Technological Progress Factors

\begin{tabular}{|l|c|c|}
\cline { 2 - 3 } \multicolumn{1}{c|}{} & \multicolumn{1}{c|}{$\begin{array}{c}\text { Random Effects } \\
\text { (GLS) }\end{array}$} & Fixed Effects \\
\hline CEAM & -2.39 & 97.78 \\
\hline CEMIG & -0.42 & 108.35 \\
\hline CENF & -0.30 & 100.29 \\
\hline ENERGIPE & -0.25 & 103.26 \\
\hline ENERSUL & -0.18 & 104.07 \\
\hline CEB & -0.16 & 104.57 \\
\hline CEAL & -0.08 & 103.80 \\
\hline COSERN & -0.08 & 104.15 \\
\hline ESCELSA & -0.05 & 105.70 \\
\hline CEMAR & -0.06 & 104.05 \\
\hline CELG & 0.03 & 105.76 \\
\hline COELCE & -0.03 & 105.48 \\
\hline SAELPA & -0.01 & 103.87 \\
\hline CEMAT & 0.01 & 104.23 \\
\hline COELBA & 0.07 & 106.60 \\
\hline CELESC & 0.05 & 106.83 \\
\hline CFLCL & 0.06 & 102.51 \\
\hline ELETROACRE & 0.11 & 100.87 \\
\hline CELPE & 0.09 & 106.15 \\
\hline COPEL & 0.12 & 107.48 \\
\hline CELPA & 0.16 & 104.87 \\
\hline CERON & 0.20 & 102.99 \\
\hline CEPISA & 0.29 & 103.52 \\
\hline CERJ & 0.35 & 106.39 \\
\hline CESP & 0.52 & 107.38 \\
\hline & & \\
\hline
\end{tabular}

\subsection{TEST FOR RANDOM EFFECTS}

We must consider that the Random Effects regression model differs from the Fixed Effects model by the inclusion of the random shock component $\boldsymbol{U}_{i}$, standing for the $i$ th observation, constant over time. In this form, the regression model is:

$Y_{i t}=\alpha+\beta^{\prime} x_{i t}+\boldsymbol{U}_{i}+€ i t$ 
where there are K regressors besides the constant term. It also assumes that since $\boldsymbol{u} \boldsymbol{i}$ is a Medindo Eficiência De Uusto No Setor De Distribuição de Energia Elétrica Brasileiro

$E\left[\boldsymbol{u}_{i}\right]=0$

$E\left[\boldsymbol{U}_{i^{2}}\right]=\sigma_{u}^{2}$

The test to be applied was created by Breusch and Pagan (1980) and is based on the use of a Lagrange multiplier, calculated from the residuals generated in the OLS estimation.

For

$$
\begin{gathered}
H_{0} \sigma_{u}^{2}=0 \\
H_{1} \sigma_{u}^{2} \neq 0
\end{gathered}
$$

the statistical test is

$$
L M=\frac{n T}{2(T-1)}\left[\frac{\sum_{i=1}^{n}\left[\sum_{i=1}^{T} e_{i t}\right]^{2}}{\sum_{i=1}^{n} \sum_{i=1}^{T} e_{i t}^{2}}-1\right]^{2}
$$

where $L M$ is the Lagrange multiplier, with $\boldsymbol{T}$ being the number of years and $\boldsymbol{e}$ the residuals generated in the OLS model. freedom

Under the null hypothesis, $L M$ has a chi-square distribution, with one degree of

This being the case, considering the OLS residuals generated and the periods in question, we obtain a Lagrange multiplier of 12.7727.

The critical values for $5 \%$ and $1 \%$ of a chi-square distribution with one degree of freedom are 3.842 and 6.635, respectively. So the Lagrange multiplier obtained in the test indicates that both critical values have high significance, unequivocally showing the influence of the error components. Thus it can be concluded that the results obtained from the Random Effects model are due to shocks, ruling out the possibility that they are systemic and thus representative.

\section{CONCLUSIONS}

According to the results obtained in the regressions, it can be inferred that the time period included in the study experienced several shocks, of different origins. In this period (1990 - 2001) the Brazilian government implemented two plans to control rampant inflation, involving replacement of the currency and changes in foreign exchange rates. Besides these 
facts, in the same period the metric to define the electricity tariff was replaced twice, one of these during the National Privatization Program, which transferred some $70 \%$ of the companies analyzed to the private sector. Another fact with great bearing in the study period was the supply shock in 2001, caused by scanty rainfall leading to energy rationing. This obliged distributors to alter their investment strategies, squeezed their revenues and increased their indebtedness, and created great pressures on the rates they paid for supply, besides permanently changing the habits of consumers, who learned to control their electricity use better. In short, the Brazilian electricity distribution segment was hit by a number of significant disturbances during the study horizon, sufficient to create breaks in the structure of the data used.

The results obtained also demonstrate that the models proposed do not obtain significant results capable of quantifying the cost efficiencies and classifying the companies as to their ability to minimize them, leading to the conclusion that all the companies were equally efficient from a standpoint of optimizing production costefficiency.

Besides the difficulties encountered because of the factors described above, notable effects caused by the heterogeneity among the companies studied must be mentioned. These differences are particularly substantial in the estimates of efficiency among companies. A similar study in the Swiss electricity market demonstrated that the results varied significantly according to the model applied, indicating that frontier cost models should not be used in isolation in formulating regulations, but rather as an additional tool, to narrow the informational gap between regulatory agents and the companies they regulate ${ }^{4}$.

\section{REFERENCES}

ACCIOLY, ANDREA and SANVICENTE, Estimação do Custo Médio de Capital de Empresas sob Processo de Regulação Econômica no Brasil, Ibmec, mimeo, 2002.

AGENCIA NACIONAL DE ENERGIA ELÉTRICA (ANEEL). METODOLOGIA DO CÁLCULO DAS TARIFAS DE USO DOS SISTEMAS DE DISTRIBUIÇÃO, Resolution 286, 1999.

ALVES FERREIRA, P.JOBIM. On the efficiency of the Argentinean Electricity Wholesale Market, University of Chicago, May 2002.

CEPE, Working Paper 08, June 2001.

ESTACHE, Antonio, MARTIN A. ROSSI and CHRISTIAN A. RUZZIER. The Case for International Coordination of Electricity Regulation: Evidence from the Measurement of Efficiency in South America. World Bank Policy Research Paper 2907, October 2002. FILIPPINI, MASSIMO and FARSI, MEHDI. Regulation and Measuring Cost Efficiency With Panel Data Models: Application to Electricity Distribution Utilities. CEPE, Working Paper FILIPPINI, MASSIMO, JORG WILD and KUENZLE.MICHAEL. Scale and Cost Efficiency in the Swiss Electricity Distribution Industry: Evidence From a Frontier Cost Approach, Paper 19, January 2003.

GREENE, William. Estimating Econometric Models with Fixed Effects, Prentice Hall, Third Edition, 1997.

JAMASB, TOORAJ and POLLITT MICHAEL. Benchmarking and Regulation of Electricity Transmission and Distribution Utilities: Lessons From International Experience. Mimeo. JAMASB, TOORAJ Reform and Regulation of the Electricity Sectors in Developing Countries. DAE Working Paper WP 0226. MIT, August 2002.

\footnotetext{
${ }^{4}$ See Farsi-Filippini (2003)

BBR, Braz. Bus. Rev. (Eng. ed., Online), 
JOSKOW, PAUL L. California's Electricity Crisis. NBER. Working Paper 8442, August 2001.

LISBOA MOTA, RAFFAELA The Restructuring and Privatization of Electricity Distribution and Supply Business in Brazil: A Cost-Benefit Analysis. DAE Working Paper 309, MIT, January 2003.

MARQUES, LUIS DAVID. Modelos Dinâmicos com Dados de Painel. CEMPRE, Working Paper 100, October 2000.

NEWBERY, DAVID M. Regulating Electricity to Ensure Efficient Competition, CEPR, Working Paper 1101, November 2001.

NEWBERY, DAVID M. Regulatory Challenges to European Electricity Liberalization, DAE Working Paper 230, MIT, May 2002.

NICHOLSON, WALTER Microeconomic Theory, Praeger, 7th Edition.

PRESCOTT, Edward. Needed: A Theory of Total Factor Productivity, International Economic Review, 1998, 39, 525-52. University of Cambridge, December 2000.

VARIAN, HAL R. Microeconomic Analysis. Prentice Hall, 3rd Edition.

VARIAN, HAL R. Microeconomia Princípios Básicos, Makron, 4th Edition. 